\title{
Protein chemical synthesis by serine and threonine ligation
}

\author{
Yinfeng Zhang, Ci Xu, Hiu Yung Lam, Chi Lung Lee, and Xuechen $\mathrm{Li}^{1}$ \\ Department of Chemistry, The University of Hong Kong, Hong Kong, People's Republic of China
}

Edited* by Samuel J. Danishefsky, Columbia University/Memorial Sloan-Kettering Cancer Center, New York, NY, and approved March 15, 2013 (received for review December 3, 2012)

\begin{abstract}
An efficient method has been developed for the salicylaldehyde ester-mediated ligation of unprotected peptides at serine (Ser) or threonine (Thr) residues. The utility of this peptide ligation approach has been demonstrated through the convergent syntheses of two therapeutic peptides-ovine-corticoliberin and Forteo-and the human erythrocyte acylphosphatase protein $(\sim 11 \mathrm{kDa})$. The requisite peptide salicylaldehyde ester precursor is prepared in an epimerization-free manner via Fmoc-solid-phase peptide synthesis.
\end{abstract}

synthetic protein | acyl transfer | chemoselective ligation

$\mathrm{L}_{\mathrm{a}}^{\mathrm{a}}$ andmark advances in the field of synthetic protein chemistry have enabled the preparation of complex, homogeneous proteins (1-3), including those that carry specific posttranslational modifications (PTMs) (4-11). Of particular significance, Danishefsky and coworkers have obtained glycosylated human folliclestimulating hormone (7) and erythropoietin (11), solely through chemical synthesis. In general, protein synthesis consists of two key phases: (i) solid-phase peptide synthesis (SPPS) allows for the generation of moderately sized peptide segments (up to $~ 30$ amino acids) (12); and (ii) chemical ligation serves to chemoselectively join these synthetic peptide fragments (13-16). In the 1970s, Kemp and coworkers conceptually devised a promising peptide ligation strategy, involving prior capture followed by acyl transfer, which has laid the foundation for the development of chemical ligation in the convergent peptide synthesis (17-22). A milestone advance in the field was the discovery, by Kent and coworkers, of native chemical ligation (NCL) (13), in which a C-terminal peptide thioester and an N-terminal cysteine-containing peptide-both in side-chain unprotected forms-are selectively coupled to generate a natural peptidic linkage (Xaa-Cys) at the site of ligation. Because the Kent NCL approach exploits the unique nucleophilicity of the cysteine thiol group, the relatively low abundance of cysteine residues in natural proteins can pose a significant challenge to NCL-based protein synthesis efforts. In an effort to expand the scope of NCL, a number of research groups have developed variants, wherein $\beta$ - or $\gamma$-thiol containing amino acids are temporarily installed on the peptide $\mathrm{N}$ terminus, thus promoting NCL-like ligation. Subsequent desulfurization serves to restore the natural amino acid at the site of ligation (23-26). Whereas this NCLdesulfurization strategy has been widely used in protein synthesis, a menu of complementary thiol-independent ligation approaches (27-34) may offer new opportunities for convergent protein synthesis. Nevertheless, these thiol-independent ligations require the installation of unique reaction functionalities, often tediously, on both sides of the $\mathrm{N}$-terminal peptide segment and the $\mathrm{C}$-terminal peptide segment to induce a chemoselective coupling reaction.

Along these lines, our laboratory has been pursuing the development of methods for ligation at $\mathrm{N}$-terminal serine and threonine residues to generate natural Xaa-Ser/Thr linkages directly, using natural serine or threonine residues at the reacting $\mathrm{N}$ terminus. In an encouraging precedent, Kemp and coworkers have examined the hemiaminal-mediated acyl transfer of 8-acetoxy-1naphthaldehyde and 2-acetoxybenzaldehyde reacting with primary amines. Under the optimal conditions, $O \rightarrow N$ acyl transfer to the less-hindered amine (i.e., glycine and benzylamine) was observed
$(17,35)$. Subsequently, an approach involving reductive amination was developed to facilitate acyl transfer $(36,37)$. Using such an imine-induced intramolecular acyl transfer concept, Tam et al. have demonstrated that a peptide containing a C-terminal glycoaldehyde can couple with a second peptide, containing an N-terminal Cys, Thr, or Ser residue, to generate a pseudoproline structure (thiazolidine or oxazolidine) at the site of ligation $(14,38,39)$. However, the resultant oxazolidine, being quite stable, has not been demonstrated to be cleavable to restore the natural peptidic linkage. In a preliminary disclosure, our laboratory recently described the coupling of an O-salicylaldehyde ester of a single amino acid or dipeptide with the 1,2-hydroxylamine moiety as found in serine and threonine, to form an $\mathrm{N}, \mathrm{O}$-benzylidene acetal linked intermediate, which, without isolation, is readily converted to the natural peptidic linkage (i.e., Xaa-Ser/Thr, Fig. 1) (40).

Having established the validity of this approach, we sought to expand upon the general concept, with the ultimate goal of developing a versatile and efficient solution to the challenge of native Ser and Thr peptide ligation (Fig. 1). We identified two significant issues that must be addressed before our concept could be successfully extended to peptide synthesis applications. First, we would need to develop a robust method for the preparation of peptide salicylaldehyde esters, which would be compatible with standard SPPS strategies. In our previous study, we had used direct coupling to prepare salicylaldehyde esters of Fmoc-protected single amino acids and pseudoproline-containing dipeptides. However, the analogous esterification of large peptide fragments via direct coupling would not be feasible, due to the potential for epimerization of the C-terminal amino acid. Second, we would need to demonstrate that the coupling reaction between peptide salicylaldehyde esters and N-terminal Ser- or Thr-containing peptides could be compatible with fully unprotected peptide substrates. We were well aware that the diverse functionality present in large sidechain unprotected peptides could potentially complicate efforts to achieve the high levels of chemoselectivity, efficiency, and preservation of chirality required for peptide ligation reactions.

The objectives outlined above have now been met, and a workable thiol-free Ser/Thr peptide ligation method has been developed. We describe herein the identification of epimerization-free conditions for the synthesis of peptide salicylaldehyde esters via Fmoc-SPPS, and the successful ligation of these substrates with unprotected N-terminal Ser or Thr peptide fragments. Moreover, the utility of this protocol has been demonstrated in the context of several biologically compelling target systems, including the human erythrocyte acylphosphatase protein.

\footnotetext{
Author contributions: Y.Z., C.X., H.Y.L., and C.L.L. performed research; X.L. designed research; Y.Z., C.X., H.Y.L., C.L.L., and X.L. analyzed data; and X.L. wrote the paper. The authors declare no conflict of interest.

*This Direct Submission article had a prearranged editor.

${ }^{1}$ To whom correspondence should be addressed. E-mail: xuechenl@hku.hk.

This article contains supporting information online at www.pnas.org/lookup/suppl/doi:10.
} 1073/pnas.1221012110/-/DCSupplemental. 
Previous work:
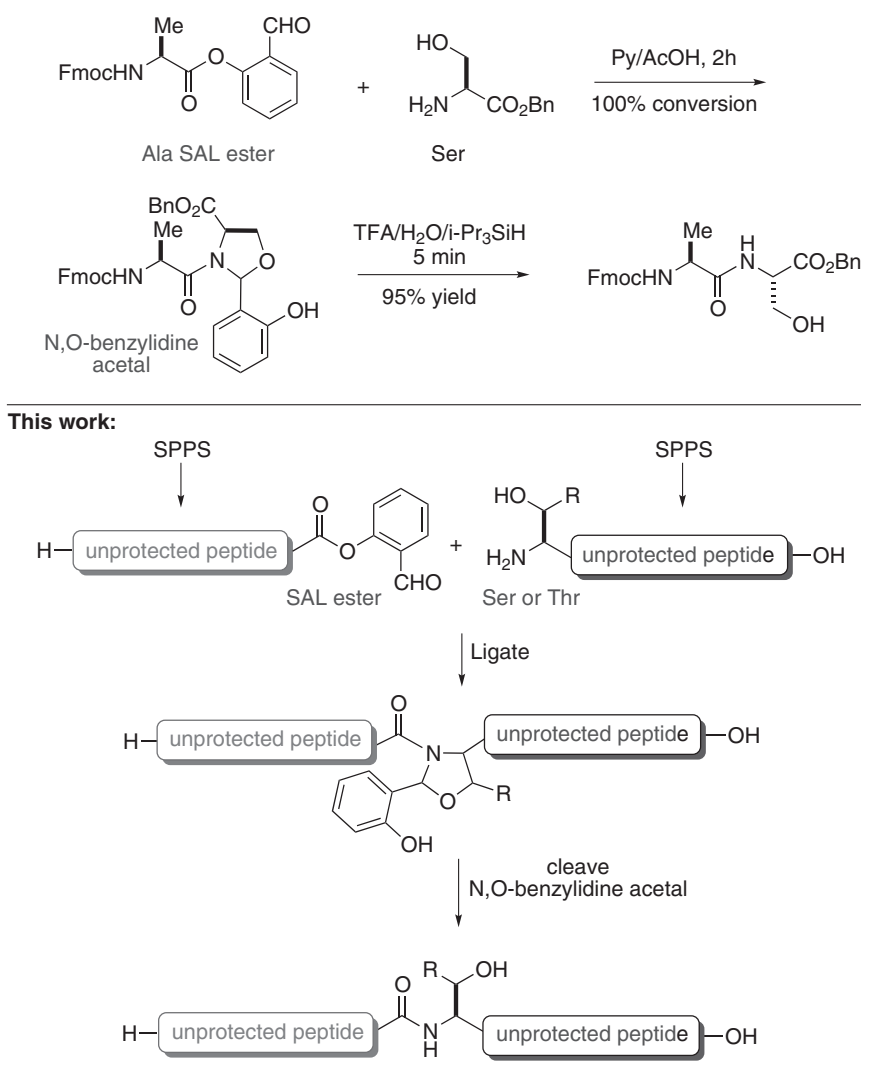

$\operatorname{Ser}(\mathrm{R}=\mathrm{H})$ or $\operatorname{Thr}(\mathrm{R}=\mathrm{Me})$

Fig. 1. Principle of salicylaldehyde ester-mediated peptide ligation at serine/ threonine sites.

\section{Results and Discussion}

Synthesis of Peptide Salicylaldehyde Esters. We first sought to devise a practical synthesis of side-chain unprotected peptide salicylaldehyde (SAL) esters. Due to the lability of the O-SAL ester under piperidine-mediated Fmoc deprotection conditions, direct preparation of the peptide SAL ester via Fmoc-SPPS would not be feasible. Inspired by recent methodological advances in FmocSPPS of peptide thioesters used in NCL (41), we adopted a postFmoc-SPPS derivatization approach. We thus developed a process wherein the peptide SAL ester could be obtained via on-resin phenolysis of the peptide $N$-acyl-benzimidazolinone (Nbz) (42) (Fig. 2). The optimized process is as follows: First, the resin-bound peptide $\mathrm{Nbz}$ is generated via Fmoc-SPPS, under the conditions developed by Blanco-Canosa and Dawson (42). The resin-bound peptide $\mathrm{Nbz}$ is then suspended in dry dichloromethane (DCM)/ THF (1/3, vol/vol), and salicylaldehyde dimethyl acetal and $\mathrm{Na}_{2} \mathrm{CO}_{3}$ are added to the flask. The reaction mixture is stirred at room temperature for $16 \mathrm{~h}$ and the concentrated filtrate is treated with TFA-based mixture to remove the side-chain protecting groups, affording the desired peptide SAL ester. Alternatively, the peptide $\mathrm{Nbz}$ may be cleaved from the Rink resin, before in-solution phenolysis. In the original Blanco-Canosa and Dawson report (42), the peptide thioester was prepared via in-solution thiolysis of the peptide Nbz. However, in our experience, the on-resin phenolysis approach provided peptide SAL esters more efficiently and cleanly. The liquid chromatography-mass spectrometry (LC-MS) trace of the crude filtrate, following on-resin phenolysis, reveals the desired peptide SAL esters, along with excess salicylaldehyde (Fig. 3).

Using this method, we prepared and purified, by reverse-phase HPLC, a series of peptide SAL esters of various lengths (6-21 amino acids) in overall yields of $20-30 \%$, based on resin loading. To ascertain whether epimerization occurs during on-resin phenolysis, we synthesized epimeric Z-DTTADA-SAL ester and Z-DTTAD $a$-SAL ester. We were pleased to observe no epimerization of the C-terminal Ala residues of these SAL esters, as determined by HPLC analysis. This strategy thus provides a reliable and facile solution to the SPPS-compatible preparation of peptide SAL esters.

Serine/Threonine Peptide Ligation. With a menu of peptide SAL esters in hand, we were now poised to investigate the extension of our salicylaldehyde ester-induced coupling to the significantly more challenging context of convergent peptide synthesis. Thus, peptide segment $\mathbf{1}$, incorporating a C-terminal SAL ester, was exposed to peptide $\mathbf{3}$, presenting a Ser residue at its $\mathrm{N}$ terminus, in pyridine acetate buffer. In the event, the two side-chain unprotected peptide segments reacted smoothly to produce the coupled peptide in nearly quantitative conversion, within $8 \mathrm{~h}$. Following acidolysis (TFA $/ \mathrm{H}_{2} \mathrm{O} / \mathrm{iPr}_{3} \mathrm{SiH}$ for $10 \mathrm{~min}$ ), the desired product, incorporating the Ala-Ser peptidic bond at the ligation site, was in hand (Table 1, entry 1). In a key demonstration, Z-DTTAD $a$-SAL ester (2) was observed to react with the same $\mathrm{N}$-terminal peptide segment (3, entry 2$)$, with no epimerization at the site of ligation, as indicated by LC-MS analysis (Fig. 4).

It is known that peptides containing $\mathrm{C}$-terminal asparagine thioesters can be resistant to ligation under standard NCL conditions, due to the propensity of the substrates to undergo cyclization to form unproductive C-terminal succinimides (43). However, under our conditions, ligation of peptides $\mathbf{4}$ and $\mathbf{5}$ proceeded rapidly, and without incident, to deliver the desired adduct, bearing an Asn-Thr sequence at the site of ligation (entry 3).
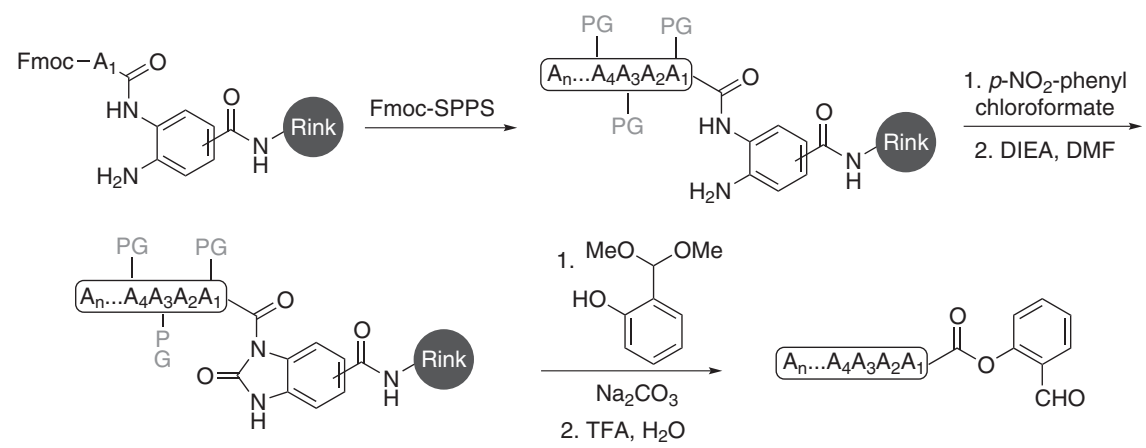

Fig. 2. Fmoc-SPPS of peptide SAL esters via on-resin phenolysis. The resin-bound peptide Nbz is generated via Fmoc-SPPS, which is subsequently subjected to on-resin phenolysis (salicylaldehyde dimethyl acetal, $\mathrm{Na}_{2} \mathrm{CO}_{3}, \mathrm{DCM} / \mathrm{THF}, 16 \mathrm{~h} ; \mathrm{TFA} / \mathrm{H}_{2} \mathrm{O}$ ) to afford the necessary peptide salicylaldehyde ester. PG: amino acid side-chain protecting group. 

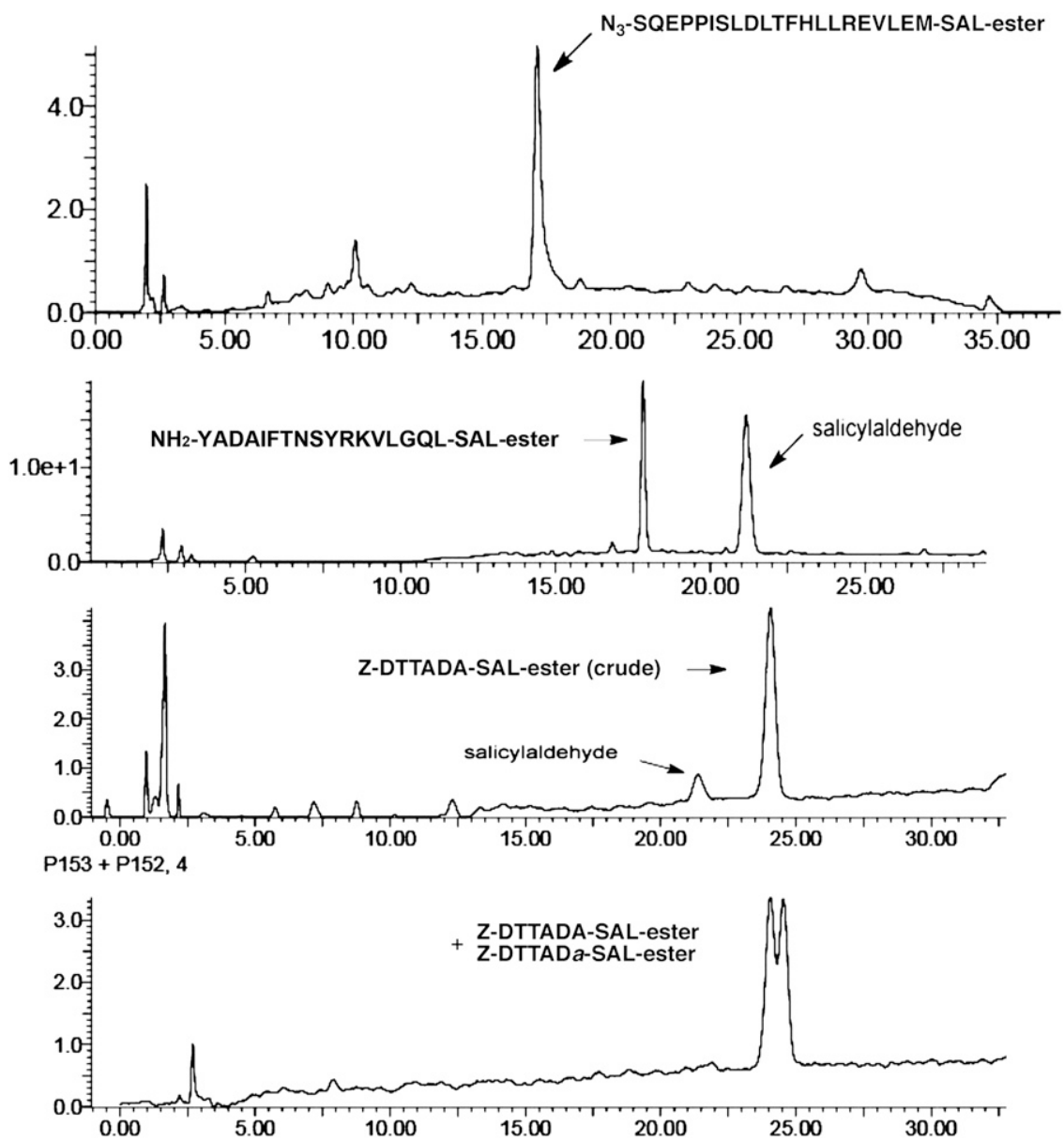

Fig. 3. Representative analytical HPLC traces of the crude reaction mixture revealing the formation of the peptide SAL ester from on-resin phenolysis. Both epimeric Z-DTTADA-SAL ester and Z-DTTADa-SAL ester were synthesized to demonstrate that no epimerization occurred at the C-terminal Ala residues of these peptide SAL esters.

Moreover, we note that the presence of unprotected Lys residues and a primary $\mathrm{N}$-terminal amine does not adversely impact the efficiency of this ligation. Although the free amino groups likely compete with the $\mathrm{N}$-terminal $\mathrm{Thr} / \mathrm{Ser}$ residue for reaction with the SAL aldehyde functionality, which could theoretically induce the hemiaminal-mediated peptide acyl transfer according to the work of Kemp and Vellaccio (35), we did not observe the unwanted product via such a pathway. Indeed, Kemp has shown that the reaction between certain amines with 8-acetoxy-1-naphthaldehyde or 2-acetoxybenzaldehyde stopped at the imine stage, without inducing acyl transfer. Under our conditions, these reversibly formed imines represent transient and nonproductive intermediate species.
We next applied our protocol to the convergent syntheses of two peptides of significant therapeutic importance, namely: ovine corticoliberin (oCRH), a 41-amino acid peptide used in the treatment of conditions of the hypothalamic pituitary adrenal axis (44); and Forteo, a 34-amino acid fragment of human parathyroid hormone used for the treatment of osteoporosis (45). To avoid the potential for self-cyclization, we elected to protect the N-terminal serine residues of the peptide SAL ester substrates with azido and Msz groups, respectively. In the event, the projected ligations proceed readily to afford oCRH (entry 4) and Forteo (entry 5) with excellent conversion. No significant side reactions were observed, apart from a minimal amount of hydrolysis of the peptide SAL ester.

Table 1. Convergent synthesis of peptides via serine/threonine ligation

\begin{tabular}{|c|c|c|c|c|c|}
\hline Entry & Peptide C-SAL-ester* & $\mathrm{N}$-terminal peptide & Time, $\mathrm{h}^{\dagger}$ & Conversion, $\%^{\ddagger}$ & Product (size) \\
\hline 1 & Z-DTTADA- (1) & H-SRQQGESNQERGARARL-NH ${ }_{2}$ (3) & 8 & $>95$ & Model (23 aa) \\
\hline 2 & Z-DTTADa- (2) & $\mathrm{H}$-SRQQGESNQERGARARL-NH $\mathrm{N}_{2}$ (3) & 8 & $>95$ & Model (23 aa) \\
\hline 3 & $\mathrm{H}_{2} N-$ VIGGVGNN- (4) & H-TLHAPTD-OH (5) & 2 & $>95$ & Model (15 aa) \\
\hline 4 & $\mathrm{~N}_{3}$-SQEPPISLDLTFHLLREVLEM- (6) & H-TKADQQAHSNRKLLDIA-OH (7) & 12 & $>90$ & oCRH (41 aa) \\
\hline 5 & Msz-SVSEIQLMHNLGKHLN- (8) & H-SMERVEWLRKKLQDVHNF-OH (9) & 1 & $>95$ & Forteo (34 aa) \\
\hline
\end{tabular}

*Prepared via on-resin phenolysis of the peptide Nbz from Fmoc-SPPS on a Rink resin.

${ }^{\dagger}$ Room temperature.

${ }^{\ddagger}$ Analysis by HPLC traces of the crude reaction mixture. 


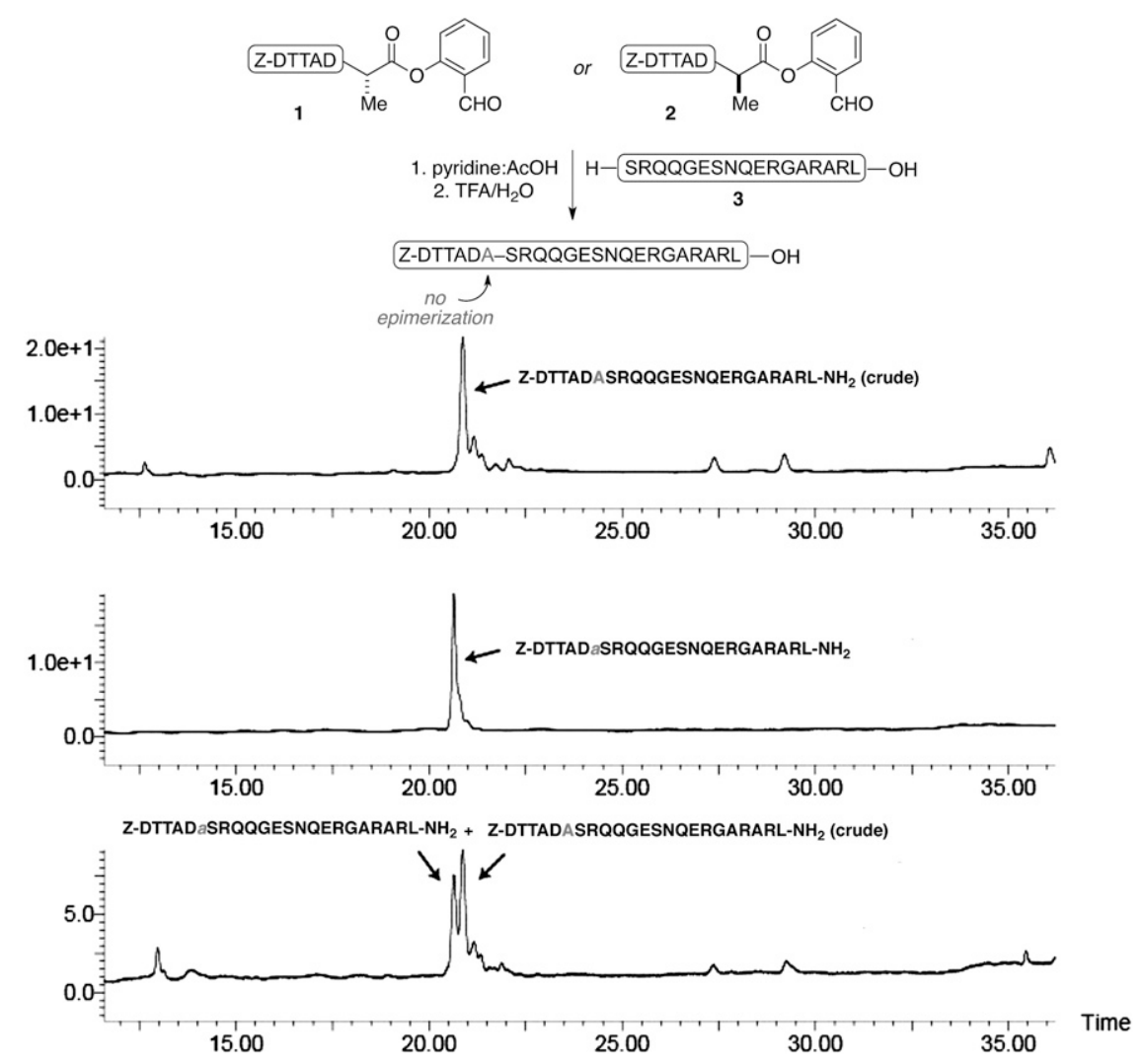

Fig. 4. Analytical HPLC traces of the ligation reaction revealing that no epimerization occurred. (Top) Crude reaction mixture of ligation using Z-DTTADA-SAL ester. (Middle) Ligation product using Z-DTTADa-SAL ester. (Bottom) Coelution of two ligation products.

Application of Ser/Thr Ligation to the Synthesis of Acylphosphatase. Finally, with the goal of evaluating the applicability of our Ser/Thr ligation method for the assembly of complex targets of biological interest, we undertook the synthesis of a challenging protein target: the human erythrocyte enzyme, acylphosphatase. Acylphosphatase ( $\sim 11 \mathrm{kDa}$ ), which catalyzes the hydrolysis of acylphosphates, is widely distributed throughout the three domains of life, although its biological roles are not fully understood (46). The human erythrocyte acylphosphatase is composed of 98 amino acid residues (47) and an acetylated $\mathrm{NH}_{2}$ terminus. Because it incorporates a number of well-distributed Ser and Thr residues, but no Cys residues, this enzyme represents an attractive platform for the demonstration of our recently developed Ser/Thr ligation capabilities.

As shown in Fig. 5, we identified potential ligation sites at Gly $^{45}-\mathrm{Thr}^{46}$ and Gly ${ }^{69}-\mathrm{Ser}^{70}$, which would allow us to divide the protein into three fragments of roughly equivalent size. Sequential Ser and Thr ligations, with unprotected peptide substrates, should deliver the acylphosphatase protein with optimal convergence. We also noted that, because both ligation sites incorporate C-terminal Gly residues, each requisite SAL ester should be readily accessed through direct coupling between the precursor peptidic acid and salicylaldehyde dimethyl acetal, without concern for epimerization.

In the event, each of the three peptide substrates $(\mathbf{1 0}, \mathbf{1 1}$, and 12) was assembled via Fmoc-SPPS on a 2-chlorotrityl chloride resin, and release from the resin was achieved through the action of 2, 2, 2-trifluoroethanol (TFE)/DCM/AcOH. With the sidechain protecting groups still in place, the intermediates corresponding to segments (46-69) and (1-45) were equipped with the requisite SAL ester functionalities through esterification with salicylaldehyde dimethyl acetal, with the aid of N, N-dicyclohexylcarbodiimide (DCC) and 4-dimethylaminopyridine (DMAP). Subsequent exposure to a trifluoroacetic acid (TFA)-based mixture afforded the SAL esters, $\mathbf{1 0}$ and $\mathbf{1 2 .}$
We first attempted Ser ligation between peptide segments $\mathbf{1 0}$ and 11. Peptide 11 (1.2 equiv) and peptide SAL ester 10 were combined in a pyridine acetate buffer $(25 \mathrm{mM}$, mole:mole, 1:1) After $10 \mathrm{~h}$ at room temperature, the ligated product was seen in 95\% conversion, determined by LC-MS analysis. Then, the reaction mixture was treated with TFA/ $\mathrm{H}_{2} \mathrm{O}(10 \mathrm{~min})$, to afford the desired ligated peptide, corresponding to segment (46-98), in $31 \%$ yield following reverse-phase HPLC purification. Fmoc removal was achieved with $\mathrm{Et}_{2} \mathrm{NH} / \mathrm{CH}_{2} \mathrm{Cl}_{2}(1.5 \mathrm{~h})$ and the resultant peptide segment (13) was used in the next step without further purification. Solubility issues encountered with peptide fragment 12 necessitated a switch to a different solvent system for the final Thr ligation step. Thus, peptides $\mathbf{1 2}$ and $\mathbf{1 3}$ underwent ready ligation in a pyridine/acetic acid (1:10) solution, to deliver the full-length polypeptide, 14, in $34 \%$ isolated yield. The electrospray ionization mass spectrometry (ESI-MS) spectrum of the purified acylphosphatase is shown in Fig. 5. The significance of the polypeptide synthesized, which comprises 19 of the 20 proteinogenic amino acids found in nature, is the demonstration of the high chemoselectivity and regioselectivity of this serine/threonine ligation strategy.

Having successfully synthesized homogeneous human erythrocyte acylphosphatase, we next hoped to evaluate its biological activity. The synthetic acylphosphatase was subjected to the folding buffer (47). The hydrolytic activity of the synthetic acylphosphatase was assayed by incubating the enzyme at $25^{\circ} \mathrm{C}$ with benzoylphosphate as the substrate in $0.1 \mathrm{M}$ acetate buffer, $\mathrm{pH} 5.3$ (48). Fig. 6 shows the UV-absorption spectra, in the region of 260-300 nm, of benzoylphosphate before, during, and after complete hydrolysis. These spectra confirm that our synthetic acylphosphatase does, in fact, exhibit the reported hydrolytic activity (48).

In summary, we have developed a robust protocol for the ligation of peptides at Ser or Thr residues. This method is distinct in its freedom from dependence on thiol-bearing residues at the ligation 


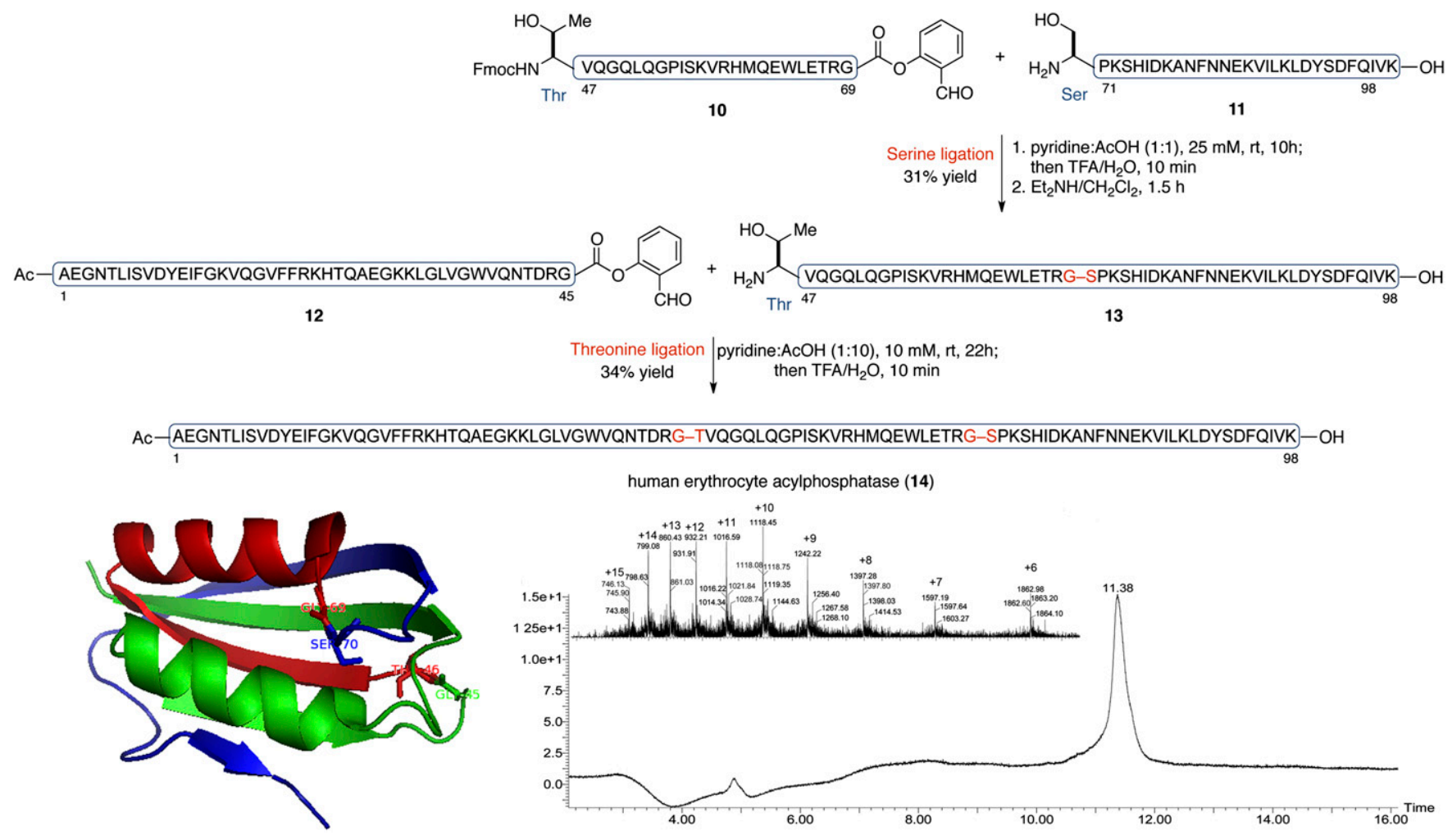

Fig. 5. Total synthesis of human erythrocyte acylphosphatase. (Upper) Synthetic scheme. Two ligations conducted at Gly ${ }^{45}$-Thr $^{46}$ and Gly ${ }^{69}-S^{20}{ }^{70}$, respectively. (Lower) Analytical HPLC trace and electrospray mass spectrum of the synthetic human erythrocyte acylphosphatase (observed molecular mass 11,173.4 Da; calculated molecular mass 11,173.1 Da).

site and indeed, the method employs native serine/threonine residues at the reacting $\mathrm{N}$-terminal peptide segment and hence requires no postligation modifications. The requisite peptide salicylaldehyde esters on the reacting C-terminal peptide segment are readily produced via Fmoc-SPPS. This method offers a number of practical advantages: it features a simple operational strategy, it does not involve complex chemical methodology, and it uses readily accessible materials. Moreover, our method is tolerant of a diverse array of functionality, including unprotected amino acid residues, free $\mathrm{N}$-terminal amines, and often-problematic $\mathrm{C}$-terminal asparagine residues. Normally sensitive $\mathrm{C}$-terminal amino acid residues do not appear to be susceptible to epimerization under our coupling conditions. Finally, our highly convergent synthesis of the human erythrocyte acylphosphatase serves to highlight the practical utility of this Ser/Thr ligation method.

The ability to engineer protein sequences using chemical synthesis will be invaluable for exploring the relationships between PTM protein structure and function/activity, and for the generation of synthetic biologics with improved properties. Considering the high abundance of serine and threonine residues in natural proteins-particularly those containing posttranslational modifications (e.g., phosphorylated or glycosylated residues)--we anticipate that this method will find wide application in the expanding field of protein chemical synthesis and provide a useful chemical biology tool to decipher the code of the protein posttranslational modifications.

\section{Materials and Methods}

All commercial materials were used without further purification. All solvents were reagent grade or HPLC grade. Anhydrous THF was freshly distilled from sodium and benzophenone. Dry DCM was distilled from calcium hydride $\left(\mathrm{CaH}_{2}\right)$. All separations involved a mobile phase of $0.05 \%$ TFA ( $\left.\mathrm{vol} / \mathrm{vol}\right)$ in acetonitrile (solvent A)/ $0.05 \%$ TFA (vol/vol) in water (solvent B). HPLC separations were performed with a Waters HPLC system equipped with a photodiode array detector (Waters 2996) using a Sunfire C18 column $(5 \mu \mathrm{m}, 4.6 \times 150 \mathrm{~mm})$ or Vydac C18 column $(5 \mu \mathrm{m}, 4.6 \times 150 \mathrm{~mm})$ at a flow rate of $0.6 \mathrm{~mL} / \mathrm{min}$ for analytical HPLC; Sunfire prep C18 optimum bed

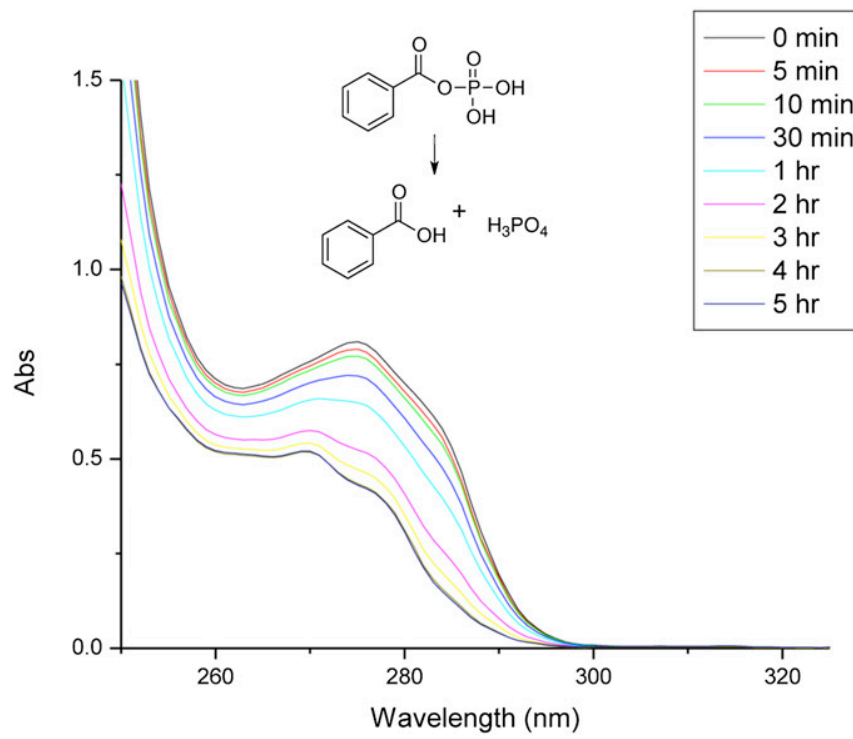

Fig. 6. UV-absorption spectra of the enzymatic hydrolysis of benzoylphosphate using the synthetic enzyme. Benzoylphosphate (1 $\mathrm{mM})$ and synthetic acylphosphatase $(60 \mathrm{nM})$ were mixed in $100 \mathrm{mM}$ acetate buffer solution ( $\mathrm{pH}$ 5.3). The reaction progress was monitored by UV absorption, indicating the complete hydrolysis of benzoylphosphate after $4 \mathrm{~h}$. Before hydrolysis: UV-absorption maxima at $275 \mathrm{~nm}$ and shoulder at $285 \mathrm{~nm}$; after hydrolysis: UV-absorption maxima at $269 \mathrm{~nm}$ and shoulder at $277 \mathrm{~nm}$. 
density (OBD) column (10 $\mu \mathrm{m}, 19 \times 250 \mathrm{~mm})$ or Vydac prep C18 column $(10 \mu \mathrm{m}, 22 \times 250 \mathrm{~mm})$ at a flow rate of $10 \mathrm{~mL} / \mathrm{min}$ for preparative HPLC. Low-resolution mass spectral analyses were performed with a Waters 3100 mass spectrometer. The UV-absorption spectra in the region 250 $350 \mathrm{~nm}$ were measured with a Varian CARY 50 Bio UV-visible spectrometer. A detailed description of materials and methods is given in SI Text.

1. Kent SBH (2009) Total chemical synthesis of proteins. Chem Soc Rev 38(2):338-351.

2. Muralidharan V, Muir TW (2006) Protein ligation: An enabling technology for the biophysical analysis of proteins. Nat Methods 3(6):429-438.

3. Nilsson BL, Soellner MB, Raines RT (2005) Chemical synthesis of proteins. Annu Rev Biophys Biomol Struct 34:91-118.

4. Gamblin DP, Scanlan EM, Davis BG (2009) Glycoprotein synthesis: An update. Chem Rev 109(1):131-163.

5. Payne RJ, Wong CH (2010) Advances in chemical ligation strategies for the synthesis of glycopeptides and glycoproteins. Chem Commun (Camb) 46(1):21-43.

6. Yamamoto N, Tanabe $Y$, Okamoto R, Dawson PE, Kajihara $Y(2008)$ Chemical synthesis of a glycoprotein having an intact human complex-type sialyloligosaccharide under the Boc and Fmoc synthetic strategies. J Am Chem Soc 130(2):501-510.

7. Nagorny $P$, et al. (2009) Toward fully synthetic homogeneous beta-human folliclestimulating hormone (beta-hFSH) with a biantennary $\mathrm{N}$-linked dodecasaccharide. Synthesis of beta-hFSH with chitobiose units at the natural linkage sites. J Am Chem Soc 131(16):5792-5799.

8. Tarrant MK, et al. (2012) Regulation of CK2 by phosphorylation and O-GlcNAcylation revealed by semisynthesis. Nat Chem Biol 8(3):262-269.

9. Sakamoto l, et al. (2012) Chemical synthesis of homogeneous human glycosylinterferon- $\beta$ that exhibits potent antitumor activity in vivo. J Am Chem Soc 134(12): 5428-5431.

10. Wilkinson BL, et al. (2012) Total synthesis of homogeneous antifreeze glycopeptides and glycoproteins. Angew Chem Int Ed Engl 51(15):3606-3610.

11. Wang P, et al. (2012) At last: Erythropoietin as a single glycoform. Angew Chem Int Ed Eng/ 51(46):11576-11584.

12. Merrifield RB (1963) Solid phase peptide synthesis. I. The synthesis of a tetrapeptide. J Am Chem Soc 85(14):2149-2154.

13. Dawson PE, Muir TW, Clark-Lewis I, Kent SBH (1994) Synthesis of proteins by native chemical ligation. Science 266(5186):776-779.

14. Liu CF, Tam JP (1994) Peptide segment ligation strategy without use of protecting groups. Proc Natl Acad Sci USA 91(14):6584-6588

15. Pattabiraman VR, Bode JW (2011) Rethinking amide bond synthesis. Nature $480(7378)$ 471-479.

16. Hackenberger CPR, Schwarzer D (2008) Chemoselective ligation and modification strategies for peptides and proteins. Angew Chem Int Ed Engl 47(52):10030-10074.

17. Kemp DS (1981) The amine capture strategy for peptide bond formation-an outline of progress. Biopolymers 20(9):1793-1804.

18. Kemp DS, Galakatos NG (1986) Peptide synthesis by prior thiol capture. 1. A convenient synthesis of 4-hydroxy-6-mercaptodibenzofuran and novel solid-phase synthesis of peptide-derived 4-(acyloxy)-6-mercaptodibenzofurans. J Org Chem 51(10):1821-1829.

19. Kemp DS, Galakatos NG, Bowen B, Tan K (1986) Peptide synthesis by prior thio capture. 2. Design of templates for intramolecular O,N-acyl transfer. 4,6-Disubstituted dibenzofurans as optimal spacing elements. J Org Chem 51(10):1829-1838.

20. McBride BJ, Kemp DS (1987) Peptide synthesis by prior thiol capture.... III. Assessment of levels of racemization during two typical thiol capture coupling reactions. Tetrahe dron Lett 28(30):3435-3438.

21. Kemp DS, et al. (1986) Peptide synthesis by prior thiol capture. 4. Amide bond for mation: the effect of a side-chain substituent on the rates of intramolecular $\mathrm{O}, \mathrm{N}$-acy transfer. J Org Chem 51(17):3320-3324.

22. Kemp DS, Carey RI (1993) Synthesis of a 39-peptide and a 25-peptide by thiol capture ligations: Observation of a 40 -fold rate acceleration of the intramolecular $\mathrm{O}, \mathrm{N}$-acyl-transfer reaction between peptide fragments bearing only cysteine protective groups. J Org Chem 58(8):2216-2222.

23. Yan LZ, Dawson PE (2001) Synthesis of peptides and proteins without cysteine residues by native chemical ligation combined with desulfurization. J Am Chem Soc 123(4): 526-533.

24. Wan Q, Danishefsky SJ (2007) Free-radical-based, specific desulfurization of cysteine: A powerful advance in the synthesis of polypeptides and glycopolypeptides. Angew Chem Int Ed Engl 46(48):9248-9252.

25. Shang S, Tan Z, Danishefsky SJ (2011) Application of the logic of cysteine-free native chemical ligation to the synthesis of Human Parathyroid Hormone (hPTH). Proc Natl Acad Sci USA 108(15):5986-5989.
ACKNOWLEDgMENTS. We thank Profs. Dan Yang, Pauline Chiu, Xiang Li, and Rory Watt and Dr. Clarence Wong for their assistance in the preparation of this manuscript; and Rebecca Wilson for her valuable assistance manuscript editing. This work was supported by the Research Grants CouncilGeneral Research Fund (HKU703811P), the National Basic Research Program of China (973 Program, 2013CB836900), and the Peacock ProgramProject Development Fund (KQC201109050074A).

26. Wong CTT, Tung CL, Li X (2013) Synthetic cysteine surrogates used in native chemical ligation. Mol Biosyst, 10.1039/C2MB25437A.

27. Nilsson BL, Kiessling LL, Raines RT (2000) Staudinger ligation: A peptide from a thioester and azide. Org Lett 2(13):1939-1941.

28. Soellner MB, Nilsson BL, Raines RT (2006) Reaction mechanism and kinetics of the traceless Staudinger ligation. J Am Chem Soc 128(27):8820-8828.

29. Bode JW, Fox RM, Baucom KD (2006) Chemoselective amide ligations by decarboxylative condensations of $\mathrm{N}$-alkylhydroxylamines and $\alpha$-ketoacids. Angew Chem Int Ed Eng 45(8):1248-1252.

30. Pattabiraman VR, Ogunkoya AO, Bode JW (2012) Chemical protein synthesis by chemoselective $\alpha$-ketoacid-hydroxylamine (KAHA) ligations with 5-oxaproline. Angew Chem Int Ed Engl 51(21):5114-5118.

31. Thomas GL, Payne RJ (2009) Phosphate-assisted peptide ligation. Chem Commun (Camb) 28(28):4260-4262.

32. Shangguan N, Katukojvala S, Greenberg R, Williams LJ (2003) The reaction of thio acids with azides: A new mechanism and new synthetic applications. J Am Chem Soc 125(26):7754-7755

33. Crich D, Sana K, Guo S (2007) Amino acid and peptide synthesis and functionalization by the reaction of thioacids with 2,4-dinitrobenzenesulfonamides. Org Lett 9(22): $4423-4426$

34. Wu X, Hu L (2007) Efficient amidation from carboxylic acids and azides via selenocarboxylates: Application to the coupling of amino acids and peptides with azides. J Org Chem 72(3):765-774

35. Kemp DS, Vellaccio F, Jr. (1975) Rapid intramolecular acyl transfer from phenol to carbinolamine-progress toward a new class of peptide coupling reagent. J Org Chem 40(20):3003-3004

36. Kemp DS, Grattan JA, Reczek J (1975) Letter: Peptide bond formation by the amine capture principle. J Org Chem 40(23):3465-3466.

37. Chen G, et al. (2006) Studies related to the relative thermodynamic stability of C-terminal peptidyl esters of O-hydroxy thiophenol: Emergence of a doable strategy for non-cysteine ligation applicable to the chemical synthesis of glycopeptides. J Am Chem Soc 128(23):7460-7462.

38. Liu CF, Tam JP (1994) Chemical ligation approach to form a peptide bond between unprotected peptide segments. Concept and model study. J Am Chem Soc 116(10):4149-4153.

39. Tam JP, Miao Z (1999) Stereospecific pseudoproline ligation of $\mathrm{N}$-terminal serine, threonine, or cysteine-containing unprotected peptides. J Am Chem Soc 121(39): 9013-9022.

40. Li X, Lam HY, Zhang Y, Chan CK (2010) Salicylaldehyde ester-induced chemoselective peptide ligations: Enabling generation of natural peptidic linkages at the serine/ threonine sites. Org Lett 12(8):1724-1727.

41. Mende F, Seitz O (2011) 9-Fluorenylmethoxycarbonyl-based solid-phase synthesis of peptide $\alpha$-thioesters. Angew Chem Int Ed Engl 50(6):1232-1240.

42. Blanco-Canosa JB, Dawson PE (2008) An efficient Fmoc-SPPS approach for the generation of thioester peptide precursors for use in native chemical ligation. Angew Chem Int Ed Engl 47(36):6851-6855.

43. Gross CM, Lelièvre D, Woodward CK, Barany G (2005) Preparation of protected peptidyl thioester intermediates for native chemical ligation by Nalpha-9-fluorenylmethoxycarbony (Fmoc) chemistry: Considerations of side-chain and backbone anchoring strategies, and compatible protection for N-terminal cysteine. J Pept Res 65(3):395-410.

44. Vale W, Spiess J, Rivier C, Rivier J (1981) Characterization of a 41-residue ovine hypothalamic peptide that stimulates secretion of corticotropin and beta-endorphin. Science 213(4514):1394-1397.

45. Saag KG, et al. (2007) Teriparatide or alendronate in glucocorticoid-induced osteoporosis. N Engl J Med 357(20):2028-2039.

46. Stefani M, Taddei N, Ramponi G (1997) Insights into acylphosphatase structure and catalytic mechanism. Cell Mol Life Sci 53(2):141-151.

47. Liguri G, et al. (1986) A new acylphosphatase isoenzyme from human erythrocytes: purification, characterization, and primary structure. Biochemistry 25(24):8089-8094.

48. Ramponi G, Treves C, Guerritore A (1966) Continuous optical assay of acylphosphatase with benzoylphosphate as substrate. Experientia 22(11):705-706. 